Original Research Paper

\title{
Occurrence of Avian Influenza H5N1 among Chicken, Duck Farms and Human in Egypt
}

\author{
${ }^{1}$ Mohamed S. Diab, ${ }^{2}$ Mohamed S. Abd EI Hafez, ${ }^{3}$ Mohamed A. Ashry and ${ }^{4}$ Wael K. Elfeil \\ ${ }^{1}$ Department of Animal Hygiene and Zoonoses, Faculty of Veterinary Medicine, \\ New Valley Branch, Assiut University, New Valley, Egypt \\ ${ }^{2}$ Poultry Diseases Department, Faculty of Veterinary Medicine, \\ New Valley Branch, Assiut University, New Valley, Egypt \\ ${ }^{3}$ Kom Hamadah Fever Hospital, El-Behera Health Directorate, Ministry of Health, Egypt \\ ${ }^{4}$ Avian and Rabbit Medicine department, Faculty of Veterinary Medicine, Suez Canal University, Ismailia, Egypt
}

Article history

Received: 6-03-2018

Revised: 7-08-2018

Accepted: 09-02-2019

Corresponding Author:

Wael K. Elfeil

Avian and Rabbit Medicine

Department, Faculty of

Veterinary Medicine, Suez

Canal University, Ismailia,

Egypt

Email: Wael.elfeil@gmail.com

\section{Introduction}

Avian influenza is a highly contagious worldwide zoonosis caused by avian influenza A virus (AIV) (Wlliams, 2016). This virus is a single strand RNA, negative sense, segmented virus that belongs to the family Orthomyxoviridae (Swayne and Glisson, 2013). Type-A influenza virus is isolated from birds and is termed avian influenza or avian flu (Alexander, 2000). The influenza virus contains two main surface segments, hemagglutinin $(\mathrm{H})$ and Neuraminidase $(\mathrm{N})$ segments (Swayne, 2017). The hemagglutinin segment includes 18

\begin{abstract}
Avian influenza (AI) H5N1 virus consider a potential threat to the poultry industry with sever zoonotic effect associated with a high risk on human being associated with the poultry production. The disease become endemic in Egypt and cause more than 359 confirmed human infection cases in the last few years. Samples (serum and tissues) collected from 160 poultry farms that suspected to be infected with H5N1. Samples were collected from 75 broiler chicken farms, 55 broiler duck farms and 30 layer duck farms. As well as 115 human samples (serum and throat swabs) collected from persons suffering from respiratory manifestations and have a history of contact with infected birds. Samples were examined using Haemagglutination inhibition (HI) test and Reverse Transcription Real Time PCR (RT- qPCR) for detection of avian influenza H5N1 virus. HI test detect H5N1 antibodies in 71 poultry samples out of 160 (44.4\%). While, RTq $(5.2 \%)$ while, RT- qPCR detect $\mathrm{H} 5 \mathrm{~N} 1$ in two human samples out of 115 human cases $(1.7 \%)$. There was an increase in rate of highly pathogenic avian influenza transmission from poultry-to-human. Adaption of AI virus was increased to duck flocks with higher percentage of vaccinal escape. Thus, there is a need to give more attention to the vaccination programs and increasing the usage of the vaccines prepared from Egyptian H5N1 virus or update the current vaccines with the isolates representing the circulating virus in the Egyptian market. All these measures will increase the protection level in poultry farms and intern decrease the risk of human infection rates.
\end{abstract}

Keywords: H5N1, Escape Mutant, Vaccinal Failure, Zoonotic AIV types while the Neuraminidase includes 11 types. Alternating types of $\mathrm{H}$ and $\mathrm{N}$ segments can produce several strains of the virus according to the pattern of combination (Tong et al., 2012). Almost the highly virulent virus -that can cause up to $100 \%$ mortality rate in poultry flocks- belongs to the H5 and H7 groups (Alexander, 2007). The highly pathogenic avian influenza (HPAI) $\mathrm{H} 5 \mathrm{~N} 1$ virus can cause significant economic losses in domestic poultry with morbidity and mortality up to $100 \%$ (Alexander, 2007). HPAI H5N1 first emerged in poultry and was further transmitted to human in Hong Kong in 1997 (Subbarao et al., 1998). 
Such highly pathogenic avian influenza virus was firstly reported in poultry population in Egypt in February 2006, from this time the virus became endemic in Egypt even in the vaccinated poultry, where Egypt is considered one of the top five countries endemic with Avian flu (Abdelwhab and Hafez, 2011; WHO, 2015). Rapidly, the first infection in human was recorded in March 2006 and human cases of H5N1 infection in Egypt started to occur due to human exposure to the virus at the poultry-human interface (Fasina et al., 2010; WHO, 2006). Although human infections remain rare and transmission of $\mathrm{H} 5 \mathrm{~N} 1$ viruses do not currently reported between people. WHO reported 676 confirmed human cases infected with $\mathrm{H} 5 \mathrm{~N} 1$ during the period between 2003 and 2014. Indonesia and Egypt were the most cumulatively affected areas (WHO, 2015).

Conferring to the WHO report in March 2018, in Egypt; there are 359 confirmed human cases infected with $\mathrm{H} 5 \mathrm{~N} 1$ virus with 120 human deaths since the first attack of H5N1 in 2006 making Egypt the highest country all over the world to report $\mathrm{H} 5 \mathrm{~N} 1$ human infection (WHO, 2018). Most of these cases related to direct contact of human with clinically or subclinical infected birds in backyards and/or live bird market (Kandeel et al., 2010).

The Egyptian poultry market has several imported (with Egyptian or non-Egyptian virus seed) and locally produced (with Egyptian virus seed) poultry vaccines against $\mathrm{H} 5 \mathrm{~N} 1$ virus. The vaccines seed maybe $\mathrm{H} 5 \mathrm{~N} 1$, H5N2, H5N3, H5N9 and recombinant ones being available as commercial vaccines. The vast majority of vaccines prepared from clades differ from the circulating H5N1 virus in Egypt. The protection level among those vaccines varies according to the level of antibody titers production (that provide expected protection against challenge with circulating Egyptian strains) and the degree of minimizing virus shedding (which may be the main cause for poultry-to-human infection route) (Arafa et al., 2012; Peyre et al., 2009; Swayne et al., 2011).

The poultry market in Egypt includes chicken, duck and turkey as main players. The chicken production consider the biggest poultry market in Egypt with approximately 350,000 grandparent bird, 10-million broiler breeders bird, 35-million layers bird and around 1.3-billion broiler bird from different breed as Arbor Arcs, Cobb, Hubbard, Ross, Avian 48. etc. The duck production in Egypt is considered the second largest constitute in the domestic poultry production sector with around 100 million ducks annually produced. The duck production in Egypt depends on the commercial farms besides a large sector in the backyard segment (Gilbert et al., 2006; Henning et al., 2010; van der Goot et al., 2008; Wibawa et al., 2014).

This study aims to check and assess:
- The current situation of poultry farm infection by H5 virus in West Egypt; (Alexandria, El-Garbia and El-Behera governorates) and the level of protection in vaccinated and non-vaccinated farms.

- The level of infection associated with heterologous vaccines.

- 3 - Human infection cases

\section{Materials and Methods}

\section{Sample Collection}

Study area: The study was performed from the beginning of September 2015 to the end of June 2016 in three different governorates of West Egypt region (ElBehera, El-Gharbia and Alexandria governorates).

The study included 160 poultry farms covering 783 rearing cycles. Each rearing cycle (average 10,000 bird per farm) was considered an independent farm. Sample collection and investigations were carried out on birds showing respiratory manifestations. The included duck and chicken farms were at El-Behera (70 farms), ElGharbia (37 farms) and Alexandria (23 farms). In addition, 30 duck layer farms from the three previous governorates were enrolled.

Flocks from 65 farms were non-vaccinated with $\mathrm{H} 5$ vaccines. Flocks from the other 95 farms received either single vaccine (duck and chicken broiler) or two dose H5 vaccine at first 9 days of life then at 70th day of life (in duck layers flocks). The vaccines used H5N1, H5N2, H5N3 or recombinant vaccines. The H5 vaccines prepared from one of the following AI H5 vaccinal seeds:A/chicken/Italy/22A/1998;RGA/chicken/VN/C58/ 2004;A/chicken/Mexico/232/1994;A/duck/Potsdam/140 2/86;A/chicken/Mexico/232/1994;A/CK/EGYPT/1063/2 010;A/duck/Anhui/1/06(H5N1);A/goose/Guangdong/1/9 6;A/chicken/Egypt/A184/2009;A/duck/Guangdong/S132 2/2010;A/chicken/Vietnam/C58/04;A/swan/Hungary/49 99/2006 or combined A/CK/Egypt/Q1995D/2010A/DK/Egypt/M2583D/2010).

Poultry samples: Nasal swabs were taken from living birds together with blood samples -for obtaining serum (20 samples from each flock)- while tissue samples lung, trachea, spleen and kidney as a pooled sample- was obtained in case of dead birds.

Samples were sent directly to laboratories of Suez Canal University and Egyptian Ministry of Health for analysis under chilled conditions.

\section{Human Samples}

A total number of 115 throat swabs as well as 115 blood samples (for serum collection) were collected from persons in contact with the examined poultry flocks with different age as shown in Table 3. Swabs were immediately transferred to the laboratory for molecular examination. 


\section{Sampling Method}

Both poultry and human samples were collected using Dacron tipped swabs. Each sample was placed in a labelled specific sterile viral transport medium; M199 solution $0.5 \%(\mathrm{w} / \mathrm{v})$ Bovine Serum Albumin (BSA), $26106 \mathrm{U} / \mathrm{L}$ penicillin, $200 \mathrm{mg} / \mathrm{L}$ streptomycin, 26106 U/L Polymyxin B, $250 \mathrm{mg} / \mathrm{L}$ gentamycin, $60 \mathrm{mg} / \mathrm{L}$ levofloxacin hydrochloride and $56105 \mathrm{U} / \mathrm{L}$ nystatin (Spackman et al., 2002).

Samples were kept on ice during collection and immediately transported to the laboratory.

\section{Sample Processing}

\section{Serum Samples}

Detection of avian influenza H5-specific antibodies in the serum samples using Haemagglutination Inhibition (HI) assays: The serum samples were inactivated at $56^{\circ} \mathrm{C}$ for $30 \mathrm{~min}$ and treated with $10 \%$ Chicken Red Blood Cells (CRBC) for one hour at $4{ }^{\circ} \mathrm{C}$ to destroy the nonspecific inhibitors. The HI antibody titers against avian influenza virus were determined using haemagglutination inhibition test (HI) with $0.5 \%$ CRBC according to the standard protocol of the OIE Manual (OIE, 2015) to measure the specific antibodies titer (AB titer).

\section{Sample Processing for Human}

In brief, the sera were treated with receptor destroying enzymes by diluting one-part serum with three parts enzyme and were incubated overnight in a $37^{\circ} \mathrm{C}$ water bath. The enzyme was inactivated by $30-\mathrm{min}$ incubation at $56^{\circ} \mathrm{C}$ followed by addition of six parts $0.85 \%$ physiological saline for a final dilution of $1 / 10$ (Kayali et al., 2008). According to WHO recommendations; a serum sample was considered as positive when the HI test antibody titer was $\geq 1: 160$.

Haemagglutination inhibition (HI) test was performed in V-bottom; 96-well microtiter plates with four haemagglutinating units (4HAU) using antigen prepared ME VAC company (Salhya, Egypt) from $\mathrm{A} /$ chicken/Egypt/M7217B/2015 (H5N1 virus) isolated and identified by the National Research Center in Egypt and represented to the circulating H5N1 virus in Egypt. Chicken erythrocytes $1 \%$ were used according to the standard protocol (Alexander et al., 2010; OIE, 2015). Results were interpreted as the reciprocal of the last well that showed complete inhibition of the haemagglutination activity of the used $\mathrm{H} 5$ antigen.

\section{Nasal Swabs}

The tip of each individual swab was placed in a collection vial containing $1 \mathrm{~mL}$ of transport medium [ $50 \%$ glycerol, $50 \%$ phosphate-buffered saline, penicillin $(2 \times 106 \mathrm{U} / \mathrm{L})$, streptomycin $(200 \mathrm{mg} / \mathrm{L})$ and amphotericin
B $(250 \mathrm{mg} / \mathrm{L})]$. The specimens were stored on ice and transported to the laboratory with $24 \mathrm{~h}$ for processing.

\section{Tissue Samples}

- RNA extraction was performed on the supernatant of tissues homogenate, nasal swabs that were taken from the dead bird and throat samples using a QIAamp Viral RNA Mini Kit (Qiagen GmbH, Hilden, Germany) according to the manufacturer's procedure

- One-step RT-PCR: PCR products Influenza type-A virus was screened using RT-qPCR assay that targeted the influenza Matrix gene. Samples were amplified using One-step (Reverse Transcription and Amplification) Real Time RT-PCR Kit (Qiagen, Germany) for detection of type-A avian influenza viruses using; Exicycler thermal block Real-Time PCR device (Bioneer, Korea), targeting the matrix gene through primers and probe mentioned by Spackman et al. (2002); Forward primer: 5'-AGA TGA GTC TTC TAA CCG AGG TCG-3', Reverse primer: 5'-TGC AAA AAC ATC TTC AAG TCT CTG-3'and probe: 5' FAM-TCA GGC CCC CTC AAA GCC GA-TAMRA-3

Positive samples for AIV were used for determination of $\mathrm{H} 5$ by using one-step specific kit for the viral subtypes QuantiTect Probe RT-PCR kit (Qiagen, Germany) at following conditions: $50^{\circ} \mathrm{C}$ for 30 min, $95^{\circ} \mathrm{C}$ for $15 \mathrm{~min}$ and 45 cycles of $94^{\circ} \mathrm{C}$ for $1 \mathrm{sec}$ and $60^{\circ} \mathrm{C}$ for $30 \mathrm{sec}$ (Eid et al., 2016).

\section{Results}

The results of examined samples in the area of study revealed 71 positive samples with high HI titer against AI virus (over $2 \log 8$ ) and suggested the exposure to Avian Influenza H5 virus. El-Gharbia governorate showed the highest percentage of farms with high HI (over $2 \log 8$ ) (57.4\%). Alexandria and El-Behera governorates was in the second level of infection or expose to AI $\mathrm{H} 5$ virus with percentages of $42.4 \%$ and $37.5 \%$ respectively, as shown in Table 1 .

This study was performed on 160 poultry farms as detailed in Table 2 . The vaccinated chicken broiler farms were 40 out of 75 farms $(53.3 \%)$. The vaccinated duck broiler farms were 25 out of 55 farms (45.4\%). The layer duck farms that received two doses of the vaccines were 30 farms.

$\mathrm{HI}$ test detect high titer of antibodies against $\mathrm{H} 5 \mathrm{~N} 1$ virus in 71 poultry samples out of $160(44.4 \%)$. RTqPCR detect $\mathrm{H} 5 \mathrm{~N} 1$ in a lower number of poultry samples; 13 out of 160 samples (8.1\%).

In the chicken and duck broiler farms, there was a higher percentage of PCR positive results in the Nonvaccinated farms than percentages of vaccinated farms. $\mathrm{HI}$ results were in the same trend. 
Table 1: Distribution of poultry sample in the three governorates

\begin{tabular}{lllll}
\hline Governorate & Total samples & Governorate $\%$ & positive samples by HI & \% of positive samples by HI \\
\hline El-Behera & 80 & $50 \%$ & 30 & $37.5 \%$ \\
Alexandria & 33 & $20.6 \%$ & 14 & $42.4 \%$ \\
Garbia & 47 & $29.4 \%$ & 27 & $57.4 \%$ \\
\hline
\end{tabular}

Table 2: The PCR and HI results in broiler and duck samples and percentage of confirmed results

\begin{tabular}{|c|c|c|c|c|c|c|}
\hline Samples & Number of samp & & $\begin{array}{l}\text { HI positive } \\
\text { samples }\end{array}$ & $\begin{array}{l}\% \text { of HI positive } \\
\text { samples }\end{array}$ & $\begin{array}{l}\text { Positive PCR } \\
\text { samples }\end{array}$ & $\begin{array}{l}\% \text { of Positive } \\
\text { PCR samples }\end{array}$ \\
\hline \multirow[t]{2}{*}{ Chicken Broiler } & Vaccinated & 40 & 14 & $35 \%$ & 1 & $2.5 \%$ \\
\hline & Non-vaccinated & 35 & 18 & $51.4 \%$ & 3 & $8.6 \%$ \\
\hline \multirow[t]{2}{*}{ Duck Broiler } & Vaccinated & 25 & 11 & $44 \%$ & 2 & $8 \%$ \\
\hline & Non-vaccinated & 30 & 15 & $50 \%$ & 3 & $10 \%$ \\
\hline Duck layers & All vaccinated & 30 & 13 & $43.3 \%$ & 4 & $13.3 \%$ \\
\hline Total & Poultry & 160 & 71 & $44.4 \%$ & 13 & $8.1 \%$ \\
\hline
\end{tabular}

Table 3: PCR and HI results in human samples and its percentage and age grouping

\begin{tabular}{llllll}
\hline Age group & No of samples & No +ve HI test & \% of HI +ve & No of PCR +ve samples & \% of PCR + ve samples \\
\hline Children & 20 & 2 & $10 \%$ & 1 & $5 \%$ \\
Adolescent & 55 & 1 & $1.8 \%$ & 0 & $0 \%$ \\
Adult & 40 & 3 & $7.5 \%$ & 1 & $2.5 \%$ \\
Total & 115 & 6 & $5.2 \%$ & 2 & $1.7 \%$ \\
\hline
\end{tabular}

In the duck layer farms category, all farms vaccinated with two does-regime using either local or imported H5 vaccines. 13 farms out of the 30 farms under investigation in this study (43.3\%) produced positive high HI titers against H5N1 virus, as shown in Table 2. All the affected farms used imported vaccines either $\mathrm{H} 5 \mathrm{~N} 1, \mathrm{H} 5 \mathrm{~N} 2, \mathrm{H} 5 \mathrm{~N} 3$ or recombinant one, while all the farms that get one or the two doses from the locally produced H5 vaccines didn't develop any signs of the $\mathrm{H} 5 \mathrm{~N} 1$ infection (unpublished data).

HI test revealed $\mathrm{H} 5 \mathrm{~N} 1$ antibodies in 6 out of 115 human serum samples (5.2\%) while, RT- qPCR detect $\mathrm{H} 5 \mathrm{~N} 1$ in 2 out of $115(1.7 \%)$ throat swabs collected from human in contact with poultry, as shown in Table 3.

\section{Discussion}

HI tests considered the primary assay being used to detect antibodies to the influenza virus HA and thus can identify functional, strain-specific antibodies in animal and human serum and it used in as a monitoring tool for immune response against $\mathrm{AI}$ viruses and have values in expected infection or expose to virus (WHO, 2002). The results of current study revealed that the overall seroprevalence of HPAI H5N1 were (44.4\%). Ameji et al. (2016) reported Lower percentage where the overall seroprevalence of $\mathrm{H} 5$ in chicken by HI was $4.2 \%$.

In the current study, 65 out of 160 poultry farms under investigated were unvaccinated. The nonvaccinated poultry farms that did not received any $\mathrm{H} 5$ vaccines and it depends mainly on the maternal immunity and biosecurity measures in preventing infections. Denoting to Table 2; the results revealed that 18 broiler farms out of $35(51.4 \%)$ and 15 broiler duck farms out of $30(50 \%)$ farms showed High HI titer results for AI H5 virus (proposed it exposed to AI H5 virus). Lower results 20.8\% and $23.1 \%$ were obtained by other authors (Madsen et al., 2013; Zheng et al., 2010 respectively).

Referring to the vaccinated group in Table 2; 95 out of 160 farms were vaccinated. Concerning broiler chicken 14 out of 40 enrolled farms (35\%) showed High HI titers against H5N1 virus (not match with the vaccination program). These affected farms were vaccinated with a single dose regime of $\mathrm{H} 5$ vaccines prepared from non-Egyptian H5 vaccinal seed.

These results give an important indication that; the circulating AI viruses in Egypt differ from the imported vaccinal seed that commonly used in Egyptian field. Thus, this is may be one of the reasons of the high percentage of vaccinal failure in the farms included in this study (Arafa et al., 2012).

These results considered to be logic results to the improper vaccination programs against $\mathrm{H} 5 \mathrm{~N} 1$ virus in endemic region and most vaccines used are no longer antigenically matched (Kayali et al., 2016).

All duck layer farms in this study, were vaccinated by two doses vaccinal regime (first on the 1-9th day old and booster on 70th day of life); $26.6 \%$ (8 out of 30 ) of the enrolled duck layer farms were vaccinated using vaccines produced from the current circulating H5N1 virus in Egypt. All these farms have been protected clinically from AI-H5 infection and did not produce any exaggerated HI results. While $74.4 \%$ (22 out of 30 ) of the enrolled duck layer farms were vaccinated with vaccines prepared from non-Egyptian vaccine seed. While $59.1 \%$ (13 out of these 22 farm) produced exaggerated high HI titers against AI-H5 virus. 
In duck farms, there was an increase in the rate of affection and vaccinal failure, which may be due to increase adaptation of the H5N1 virus in ducks in Egypt. So, this may lead to developing a new strain from the virus that able to escape from the vaccines or develop a new avian influenza outbreak (Grund et al., 2011).

The PCR results confirmed the affection of 13 farms out of $160(8.1 \%)$ farms enrolled in this study with the AI-H5 virus. This lower percentage in comparison with HI detected data (44.4\% of enrolled farms) is might be due to swaps and tissue collection time as it might be collected after the virus replication course so the RTPCR system could not detect the virus RNA in the tissue.

In human sector, However, Egypt as at the end of 2015 had the highest number of confirmed human cases (346) across the globe and with 116 deaths recorded, second to Indonesia (WHO, 2015). In the current study there was six confirmed human cases out of 115suspected cases using the HI test to be exposed to AI-H5 virus. PCR data showed two confirmed human cases out of the 115-suspected cases and thus may reflect the time of sampling as maybe samples collected after the virus elimination from the body, so could not detect the virus RNA in the samples but detect the antibodies associated with the virus previous presences. Lower results were recorded by (Huo et al., 2012) who confirmed that the Seropositive rate of H5N1 infection in human by HI test was $2.61 \%$. As well as, results were obtained by Wang et al. (2008) who confirmed that all tested persons were seronegative.

The antigenic drift in AI-H5N1 resulting in lower matching degree between vaccines seeds and circulating viruses in Egyptian market; consequently needs further evaluation of vaccine seed strains (Kaoud et al., 2014). Some previous reports have indicated that improper antigenic matching between vaccines and circulating viruses might reduce vaccine efficacy (Chen, 2009) and this may explain the results in vaccinated farms and develop either exaggerated high HI titer against AI-H5 virus or developed clinical signs. Proper control of AI required accompany vaccination process by other control measures such as depopulation, quarantines and increased surveillance. The long-term application of vaccination without eradication may result in the selection of the antigenically divergent strains, which compromises the value of vaccination and may lead to vaccinal failure (Lee and Suarez, 2005).

Eventually, vaccination became the main available tool to control AI-H5 virus in Egypt, as other tools of the control plan became relatively neglected. This strategy failed to control the spread of $\mathrm{H} 5 \mathrm{~N} 1$ virus, given that outbreaks in poultry continued to occur. The genetic dissimilarity and poor reactivity between commercial vaccines and currently circulating viruses indicate that the vaccines are not efficacious in the field (Kayali et al., 2016).
Vaccinal failure may be a reason of the high incidence of AI-H5 in human in Egypt (Arafa et al., 2012). For example in the 2014-2015 winter season, $\mathrm{H} 5 \mathrm{~N} 1$ was circulating heavily in poultry flocks resulting in unexpected number of human infections (Kayed et al., 2016). Consequently, the constant exposure to infected poultry may lead to constant increase of human infection cases (Fasanmi et al., 2017).

\section{Conclusion}

The data obtained from this study suggested that the diagnosis and monitoring of avian influenza $\mathrm{H} 5 \mathrm{~N} 1$ virus infection should be based on RT-PCR techniques. It will be more appropriate to use vaccines based on the isolated virus strain from Egypt instead of non-Egyptian vaccine seeds. In addition, it is rather important to raise awareness among workers in poultry farms about the values of proper vaccination program and adoption of proper biosafety measures to reduce the risk of avian influenza transmission from poultry-to-human.

\section{Author's Contributions}

Mohamed S. Diab, Mohamed S. Abd El Hafez, Mohamed A. Ashry and Wael K. Elfeil: Conceived and designed the experiments.

Mohamed S. Abd El Hafez and Mohamed A. Ashry: Performed the experiments.

Mohamed S. Diab and Wael K. Elfeil: Analyzed the data.

Mohamed S. Diab, Mohamed S. Abd El Hafez and Mohamed A. Ashry: Contributed reagents/materials/ analysis tools.

Mohamed S. Abd EI Hafez, Mohamed S. Diab and Wael K. Elfeil: Wrote the paper.

\section{Ethics}

The experiment approved by Assiut University ethical committee.

\section{References}

Abdelwhab, E. and H. Hafez, 2011. An overview of the epidemic of highly pathogenic $\mathrm{H} 5 \mathrm{~N} 1$ avian influenza virus in Egypt: Epidemiology and control challenges. Epidemiology Infection, 139: 647-657.

Alexander, D.J., 2000. A review of avian influenza in different bird species. Veterinary Microbiology, 74: 3-13.

Alexander, D.J., 2007. An overview of the epidemiology of avian influenza. Vaccine, 25: 5637-44. 
Alexander, D.J., R.J. Manvell, R. Irvine, B.Z. Londt and B. Cox et al., 2010. Overview of incursions of Asian $\mathrm{H} 5 \mathrm{~N} 1$ subtype highly pathogenic avian influenza virus into Great Britain, 2005-2008. Avian Diseases, 54: 194-200.

Ameji, O., L. Saidu and P. Abdu, 2016. Sero-prevalence of avian influenza in poultry in Kogi State, Nigeria. Science, 6: 1-6.

Arafa, A., D. Suarez, S.G. Kholosy, M.K. Hassan and S. Nasef et al., 2012. Evolution of highly pathogenic avian influenza H5N1 viruses in Egypt indicating progressive adaptation. Arch Virol., 157: 1931-47. Chen, H., 2009: Avian influenza vaccination: The experience in China. Rev. Sci. Tech., 28: 267-74.

Eid, H.I., A.M. Algammal, S.A. Nasef, W.K. Elfeil and G.H. Mansour, 2016. Genetic variation among avian pathogenic $E$. coli strains isolated from broiler chickens. Asian J. Animal Vet. Advances, 11: 350-356.

Fasanmi, O.G., I.A. Odetokun, F.A. Balogun and F.O. Fasina, 2017. Public health concerns of highly pathogenic avian influenza $\mathrm{H} 5 \mathrm{~N} 1$ endemicity in Africa. Veterinary World, 10: 1194.

Fasina, F., V. Ifende and A. Ajibade, 2010. Avian influenza A $(\mathrm{H} 5 \mathrm{~N} 1)$ in humans: Lessons from Egypt. Euro Surveill 15: 19473.

Gilbert, M., P. Chaitaweesup, T. Parakamawongsa, S. Premashthira and T. Tiensin et al., 2006. Freegrazing ducks and highly pathogenic avian influenza, Thailand. . Emerging Infectious Dis., 12: 227-34.

Grund, C., E.S.M. Abdelwhab, A.S. Arafa, M. Ziller and M.K. Hassan et al., 2011. Highly pathogenic avian influenza virus H5N1 from Egypt escapes vaccineinduced immunity but confers clinical protection against a heterologous clade 2.2.1 Egyptian isolate. Vaccine, 29: 5567-5573.

Henning, J., H. Wibawa, J. Morton, T.B. Usman and A. Junaidi et al., 2010. Scavenging ducks and transmission of highly pathogenic avian influenza, Java, Indonesia. Emerg. Infect. Dis., 16: 1244-50.

Huo, X., R. Zu, X. Qi, Y. Qin and L. Li et al., 2012. Seroprevalence of avian influenza A (H5N1) virus among poultry workers in Jiangsu Province, China: An observational study. BMC Infect. Diseases, 12: 1.

Kandeel, A., S. Manoncourt, E. Abd el Kareem, A. Mohamed Ahmed and S. El-Refaie et al., 2010. Zoonotic transmission of avian influenza virus (H5N1), Egypt, 2006-2009. Emerg. Infect. Dis., 16: 1101-1107.

Kaoud, H., H. Hussein, A. El-Dahshan, H. Kaliefa and M. Rohaim, 2014. Co-circulation of avian influenza viruses in commercial farms, backyards and live market birds in Egypt. Int. J. Vet. Science Med., 2: 114-121.

Kayali, G., A. Kandeil, R. El-Shesheny, A.S. Kayed and A.M. Maatouq et al., 2016. Avian Influenza $\mathrm{A}(\mathrm{H} 5 \mathrm{~N} 1)$ Virus in Egypt. Emerging Infect. Dis., 22: 379-388.
Kayali, G., S.F. Setterquist, A.W. Capuano, K.P. Myers and J.S. Gill et al., 2008. Testing human sera for antibodies against avian influenza viruses: Horse RBC hemagglutination inhibition vs. microneutralization assays. J. Clinical Virology, 43: 73-78.

Kayed, A., A. Kandeil, R. El Shesheny, M. Ali and G. Kayali, 2016. Active surveillance of avian influenza viruses in Egyptian Poultry 2015. Eastern Mediterranean Health J., 22: 557.

Lee, C.W. and D.L. Suarez, 2005. Avian influenza virus: Prospects for prevention and control by vaccination. Anim. Health Res. Rev., 6: 1-15.

Madsen, J.M., N.G. Zimmermann, J. Timmons and N.L. Tablante, 2013. Avian influenza seroprevalence and biosecurity risk factors in Maryland backyard poultry: A cross-sectional study. PLoS One, 8: e56851.

OIE, 2015. Manual of diagnostic tests and vaccines for terrestrial animals. OIE, Rome, Italy.

Peyre, M., H. Samaha, Y.J. Makonnen, A. Saad and A. Abd-Elnabi et al., 2009. Avian influenza vaccination in Egypt: Limitations of the current strategy. J. Molecular Genetic Med., 3: 198-204.

Spackman, E., D.A. Senne, T. Myers, L.L. Bulaga and L.P. Garber et al., 2002. Development of a real-time reverse transcriptase PCR assay for type a influenza virus and the avian $\mathrm{H} 5$ and $\mathrm{H} 7$ hemagglutinin subtypes. J. Clinical Microbiol., 40: 3256-3260.

Subbarao, K., A. Klimov, J. Katz, H. Regnery and W. Lim et al., 1998. Characterization of an avian influenza A (H5N1) virus isolated from a child with a fatal respiratory illness. Science, 279: 393-6.

Swayne, D.E. and J.R. Glisson, 2013. Diseases of poultry. Wiley-Blackwell, Ames, Iowa.

Swayne, D.E., 2017. Animal influenza. John Wiley and Sons, Inc, Ames, Iowa.

Swayne, D.E., G. Pavade, K. Hamilton, B. Vallat and K. Miyagishima, 2011. Assessment of national strategies for control of high-pathogenicity avian influenza and low-pathogenicity notifiable avian influenza in poultry, with emphasis on vaccines and vaccination. Rev. Sci. Tech., 30: 839-70.

Tong, S., Y. Li, P. Rivailler, C. Conrardy and D.A.A. Castillo et al., 2012. A distinct lineage of influenza A virus from bats. Proceedings of the National Academy Sci., 109: 4269-4274.

van der Goot, J.A., M. van Boven, S.A. van de Water, G.P. Sandra and M.C. de Jong et al., 2008. Transmission of highly pathogenic avian influenza H5N1 virus in Pekin ducks is significantly reduced by a genetically distant $\mathrm{H} 5 \mathrm{~N} 2$ vaccine. Virology, 382: 91-7. 
Wang, H., Z. Feng, Y. Shu, H. Yu and L. Zhou et al., 2008. Probable limited person-to-person transmission of highly pathogenic avian influenza A (H5N1) virus in China. Lancet, 371: 1427-1434.

WHO, 2002. WHO Manual on Animal Influenza Diagnosis and Surveillance, WHO/CDS/CSR/NCS/2002.5 Rev. 1.

WHO, 2006. Confirmed human cases of avian influenza A (H5N1). Geneva, Switzerland: World Health Organization. World Health Organization, Geneva, Switzerland.

WHO, 2015. Cumulative number of confirmed human cases for avian influenza $\mathrm{A}(\mathrm{H} 5 \mathrm{~N} 1)$ reported to WHO, 2003-2015 [cited 2015 Apr 15]. In W. H. Organization (Ed.): EN_GIP 20150303. WHO, World Health Organization.

WHO, 2018. Cumulative number of comfirmed human cases for avian influenza A $(\mathrm{H} 5 \mathrm{~N} 1)$ reported to WHO 2003-2018.
Wibawa, H., J. Bingham, H. Nuradji, S. Lowther and J. Payne et al., 2014. Experimentally infected domestic ducks show efficient transmission of Indonesian $\mathrm{H} 5 \mathrm{~N} 1$ highly pathogenic Avian Influenza virus, but lack persistent viral shedding. Plos One.

Wlliams, S.M., 2016. A laboratory manual for the isolation, identification and characterization of avian pathogens. American Association of Avian Pathologists, Jacksonville, Fl.

Zheng, T., B. Adlam, T. Rawdon, W. Stanislawek and S. Cork et al., 2010. A cross-sectional survey of influenza A infection and management practices in small rural backyard poultry flocks in two regions of New Zealand. New Zealand Vet. J., 58: 74-80. 